\title{
Italian Web Job Vacancies for Marketing-Related Professions
}

\author{
Mario Mezzanzanica*
}

\begin{abstract}
Digital revolution, globalization and the re-organisation of production and service companies have heavily modified the demand for skills and specific occupations. Here, the problem of analyzing web job vacancies is attracting increasing research interest from public organizations, employment agencies, and private companies, as it could reveal how web labour market demand is evolving with time, by focusing on the skills required of applicants by employers. A study conducted on the Italian web labour market focused on three distinct professional areas, namely, Communications, Sales, and Administration \& Finance.
\end{abstract}

Keywords: Globalisation; Digital Economy; Digital Revolution; Spin-Off; Job Vacancies; Marketing Professions

\section{Digital Revolution and Globalisation}

In the past few decades, significant forces and factors have dramatically changed the nature and characteristics of the labour market in both advanced and developing countries. Digital revolution, globalization and the re-organisation of the production and service companies have heavily modified the demand for skills and specific occupations. In global markets [...] the success is determined by the capacity to manage accumulated knowledge (inside-out knowledge resources) and the sum of knowledge that can be acquired externally through network relations (outside-in knowledge resources) (Brondoni, 2011). Furthermore, population ageing in advanced economies intensifies the need for continued training, and is likely to affect the structural demand for digital skills, in particular those related to financial, sales and marketing occupations.

The impact of these elements on the labour market is multifaceted. On the one side, several jobs are today disappearing whereas new jobs are emerging in the labour market. Some of these are a variant of existing jobs whilst others are new jobs that were inexistent until few years ago. "Globalisation, lean production, outsourcing, networking, digital ICT and the convergence of technologies combine to substantially modify company management, focusing company policies on the development of innovations based on smart innovation” (Brondoni, 2015).

On the other side the quantity and quality of the demand for skills and qualifications associated to the new labour market has changed dramatically. In

* Associate Professor of Information System, University of Milan-Bicocca (mario.mezzanzanica@unimib.it)

Mezzanzanica, M. (2015). Italian Web Job Vacancies for Marketing-Related Professions, Symphonya. Emerging Issues in Management (symphonya.unimib.it), 3, 110-124. 
particular, digital skills are requested to perform new jobs as well as to cope with existing jobs that have changed considerably. This phenomenon has a relevant impact on manufacturing industries (e.g., Industry 4.0), service companies as their business process is strongly affected by services innovation and customer engagement (e.g., marketing automation).

Which occupations will grow in the future and where? What skills will be demanded the most in the next years? Those are the questions that are at the forefront of the debate among managers, economists and policymakers.

In such a scenario, the Web plays a crucial role as it allows matching labour market demand and supply in a easily and timely way. Indeed, today a growing number of employers has been using the web to advertise job opportunities. This makes available a huge mass of data that is useful for addressing the information needs of several labour market stakeholders, including public organisations, educational and employment agencies, and analysts. Here, Labour Market Intelligence aims at turning these data into knowledge to provide reduced time-tomarket insights and fine-grained analyses of labour market dynamics.

Analysis of the web labour market data is of increasing importance for both analysts and labour market specialists, as recently acknowledged by the European Commission (The European Commission 2010, 2008) and the UK Commission for Employment and Skills (Bimrose and Barnes 2010). Roughly, the analysis of the web labour market allows an understanding of labour market dynamics by identifying trends, skills and occupations according to real market expectations. This, in turns, enables and assists evidence-based policy making. In such a scenario, the term Labour Market Intelligence (LMI for short) refers to all the activities aimed at extracting knowledge (and thus value) from web labour market data for strengthening the decision-making process. These data are usually from web job vacancies, namely unstructured text posted by employers on specialized websites. Usually, they are composed of a title (specifying the job position) and a full description that sets out the job duties along with the contract terms and conditions, and the skills required. The use of web job vacancies to support Labour Market Intelligence (LMI) represents a novelty with respect to the classical survey-based labour market analyses. Specifically, it allows one to (i) significantly reduce the analysis time-to-market, (ii) analyse labour market dynamics at a very fine-grained geographical level, and (iii) disclose knowledge not framed in an a-priori model (as in surveys, see, e.g. (Eurostat 2016)), to identify unforeseen behaviour in the web labour market. As a major contribution, the analysis of web job vacancies allows labour market analysts and specialists to make sense of the European labour market dynamics and trends, by performing text classification via machine-learning to classify web job vacancies in a standard well-established taxonomy. This taxonomy acts like a lingua franca, enabling the observation and comparison of different web labour markets across national borders by overcoming the linguistic boundaries. For this reason, we classify job vacancies with respect to the European Skills, Competences, Qualifications and Occupations (ESCO) ${ }^{\mathrm{i}}$ taxonomy, performing text classification based on machine learning techniques. Notice that ESCO currently represents the most accurate and standardized taxonomy of labour occupations and skills. Secondly, the analysis of web job vacancies reduces the 'time-to-market' of the analyses in comparison with that of classical survey-based analyses, thus facilitating prompt policy evaluation and decision tasks. 


\subsection{What is WollyBI and How It Works}

WollyBI is a product of Tabulaex, a spin-off of the University of Milan-Bicocca. WollyBI aims at analysing the big data of the web labour market for supporting decision making activities of several stakeholders. From a methodological point of view, WollyBI follows the KDD (Fayyad, Piatetsky-Shapiro and Smyth, 1996) approach (Knowledge Discovery in Databases) that works as follows. It scrapes web job vacancies from several heterogeneous web sources ( including newspaper websites, employment agencies and job boards). As a second step, it classifies these job vacancies on the most accurate ESCO level (the 4th) through the use of machine learning algorithms. Then, it extracts skills requested in the advertisements using Information Extraction techniques, recognising the ESCO skills and identifying new potential ones to better represent the labour market expectations. WollyBI is rapidly emerging as a powerful solution to support Labour Market Intelligence as it enables understanding, monitoring, and analysing labour market dynamics and trends.

In recent years, classifying and analysing job vacancies and occupations published on the web has been a challenging issue due to the difficulties in handling unstructured texts and different lexical matter used in the vacancies. Most of the classification approaches proposed in the literature are based on different taxonomies (both public and proprietary), and they are generally performed by experts in a non-automatic way. For instance, in (Elias and Purcell, 2004) the authors study the graduate labour market in the UK using job vacancies classified by experts according to the Standard Occupational Classification (SOC, 2000) without the support of any automated tool. On the other hand, the automatic extraction of meaningful information from unstructured texts has been mainly devoted to supporting the e-recruitment process (see. e.g., Lee, 2011). Concerning companies, the need to support Human Resources (HR) activities is strong; as a consequence, a growing amount of commercial skill-matching products has been developed in recent years, for instance BurningGlass, Workday, Pluralsight, EmployInsight, and TextKernel, just to cite a few.

In such a scenario, the aim of WollyBI differs in two respects. First, it sorts job vacancies according to a target classification system for building a (languageindependent) knowledge base to support labour market analysts, rather than matching resumés of job vacancies. Second, it classifies job vacancies according to a standard international classification system rather than a proprietary (and closed) internal taxonomy, and thus outcomes can be compared between different countries. From a technical perspective, WollyBI utilises text classification through machine learning (see, e.g., (Sebastiani, 2002), (Amato, et al., 2015), (Dusi, et al., 2016) to classify job vacancies by the ISCO/ESCO taxonomy.

\subsection{Research Question and Paper Structure}

This paper seeks to give an example of the potential that the analysis of big data can disclose for analyzing the web labour market in terms of both occupations and skills. This paper focuses on how the knowledge base synthesized from big data can enable analysts and labour market specialists to analyse and understand the dynamics of the web labour market, by letting the data speak through a data driven approach. This new paradigm, which the use of big data provides, would allow one 
to identify new potential occupations according to labour market expectations. In addition, it would allow one to study the relevance of skills in different professional categories in order to observe how the labour market professions change promptly in comparison to classical survey-based approaches. Specifically, in this paper we focus attention on three distinct areas of occupations: (i) Marketing and Communications; (ii) Sales and (iii) Administration, Finance and Control. The analyses were performed on the WollyBI knowledge base we describe below, containing over 1.9 million job vacancies collected since 2013. In this paper, for each area we provide a fine-grained analysis of trends, industry sector, job geographical distribution, and the skills requested in the job vacancies. Finally, we also provide some new potential occupations identified through the use of topic model algorithms.

$\square$ Box I: Web job vacancy example.

"For a mechanical company in Trezzano $S / N$ we are looking for an assistant for marketing activities. The right candidate for the marketing assistant role will be a graduate with a minimum of 2 years experience in B2B marketing and have excellent communications skills. The role is to provide marketing, design and communications support to the marketing manager, assisting with various marketing activities. Excellent spoken and written English is essential. Temporary contract finalized to permanent employment. Skills required: - excellent communications skills - excellent in written and spoken English excellent knowledge of Microsoft Office package, graphic software (photoshop) and editing video software"

Such a job vacancy is first classified according to the ESCO occupations taxonomy, and then the WollyBI system extracts the most relevant skills linking them to the ESCO skills hierarchy. In the example above, the occupation requested has the code 3312: Market Assistant . Furthermore, the skills that can be extracted are "MS Office" (ESCO skill code: 15371), graphic programs (ESCO skill code: 19231), "Editing, video production (ESCO skill code: 23083)". Focusing on soft (aka trasversal) skills, here we can extract "English" and "Language and Communication".

The paper is organized as follows. In Section 2 we introduce and describe the three areas analyzed, providing an overview of the main job positions that each area comprises. Then, for each area, we focus on the time dimension, i.e., the number of vacancies (Section 3), the sector specified in the vacancy (if provided in the vacancy text) (Section 4), and a territorial analysis (Section 5). In Section 6 we report on the skills (both hard and soft) as extracted and in line with the ESCO taxonomy, while in Section 7 we report on some new potential occupations identified by means of topic modeling algorithms. Finally, the concluding remarks close the paper. 


\section{Occupational Dynamics in Three Distinct Areas}

In Table 1 we report on the distribution of web job vacancies over the three distinct areas, that account for $34 \%$ of the overall job vacancies collected between February 2013 and November 2016. In particular, the Sales area surpasses both the Marketing and Communication and the Administration and Finance areas, which account for $7 \%$ and $6 \%$ respectively.

Table 1: Number of Vacancies by Area

\begin{tabular}{|l|c|c|}
\hline \multicolumn{1}{|c|}{ Area } & Number of vacancies & $\boldsymbol{\%}$ \\
\hline Sales & $\mathbf{2 3 3 . 4 6 0}$ & $\mathbf{2 1 \%}$ \\
\hline Informative Systems & 141.322 & $13 \%$ \\
\hline Production & 127.577 & $12 \%$ \\
\hline Research and Development, Engineering & 126.971 & $12 \%$ \\
\hline General services, Secretary, Safety & 119.131 & $11 \%$ \\
\hline Supply Chain & 114.943 & $10 \%$ \\
\hline Marketing and Communication & $\mathbf{7 4 . 9 6 7}$ & $\mathbf{7 \%}$ \\
\hline Project Management and Quality & 62.024 & $6 \%$ \\
\hline Administration and Finance & $\mathbf{6 1 . 6 6 5}$ & $\mathbf{6 \%}$ \\
\hline Human Resources & 32.899 & $3 \%$ \\
\hline General Direction & 3.630 & $0 \%$ \\
\hline \multicolumn{1}{|c|}{ Total } & $\mathbf{1 . 0 9 8 . 5 8 9}$ & $\mathbf{1 0 0 \%}$ \\
\hline
\end{tabular}

Description of the selected Areas:

- Administration and Finance: this includes professionals engaged in both general and analytical accountant tasks aimed at producing primary financial documents, the control of financial flows and annual needs, and verifying allocation of resources.

- Marketing and Communication: this includes professionals engaged in the promotion of the company (both direct and indirect) and its product brands, and in the implementation of all the interventions aimed at commercializing products and services.

- Sales: this includes professionals who are in charge of promoting trade and business contracts between the company and potential customers, according to the business goals identified by the company itself.

In the following boxes we give a brief description of the occupations that each area comprises, as they emerge from the web labour market. Notice that three professionals emerge as quite significant in terms of frequency, namely "Business services agents" in the Sales area, "Public relations professionals" in the Marketing and Communication, and "Administrative and executive secretaries" in the Administration and Finance area.

$\square$ Box II: Area Sales.

This area is composed of the following ESCO occupations, i.e. (i) Business services agents; (ii) Shop sales assistants; (iii) Shop supervisors ;(iv) Sales and marketing managers and (v) Shop keepers . 
The principal occupation requested in this area is "Business services agents" accounting for $63 \%$ ( or about 146,000 vacancies). Then there is the request for "Shop sales assistants" accounting for 31\% (with more than 71,000 vacancies), followed by the not negligible request for "Shop supervisors" (4\%, with up to 10,000 vacancies) and "Sales and marketing managers" (2\%, with up to 4,000 vacancies), whilst the demand for "Shop keepers" is quite negligible (500 vacancies).

$\square$ Box III: Area Marketing and Communications.

This area is composed of the following ESCO occupations, i.e. (i) Public relations professionals; (ii) Information and communications technology operations technicians; (iii) Advertising and marketing professionals and (iv) Advertising and public relations managers.

The principal occupation requested in this area is "Public relations professionals" accounting for 41\% (about 30,000 vacancies). Then there is the request for "Advertising and marketing professionals" accounting for $31 \%$ (with more than 23,000 vacancies), followed by the not negligible request for "Information and communications technology operations technicians" (26\%, with up to 19,000 vacancies), whilst the demand for "Advertising and public relations managers" is quite negligible ( $2 \%$, being 1,700 vacancies $)$.

\section{$\square$ Box IV: Area Administration and Finance.}

This area is composed of the following ESCO occupations, i.e. (i) Administrative and executive secretaries; (ii) Accounting and bookkeeping clerks; (iii) Accountants; (iv) Payroll clerks; (v) Statistical, finance and insurance clerks, and (vi) Financial analysts4. In this area, the most requested occupation is "Administrative and executive secretaries" accounting for 40\% (or about 24,000 vacancies). Then there is the request for "Accounting and bookkeeping clerks" accounting for $22 \%$ (with more than 13,000 vacancies), followed by the not negligible request for "Accountants" (16\%, with up to 10,000 vacancies), "Payroll clerks" (15\%, with up to 9,000 vacancies), "Statistical, finance and insurance clerks" (5\%, with up to 2,700 vacancies), whilst the demand for "Financial analysts" is quite negligible (1,300 vacancies).

Figure 1: Occupation Profiles of Vacancies in area SALES

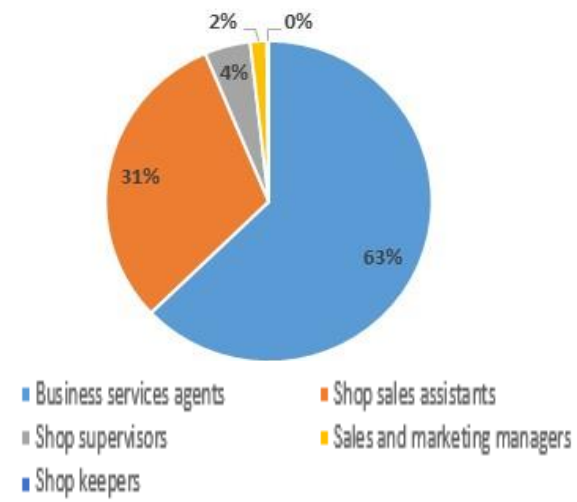


Figure 2: Occupation Profiles of Vacancies in area MARKETING AND COMMUNICATION

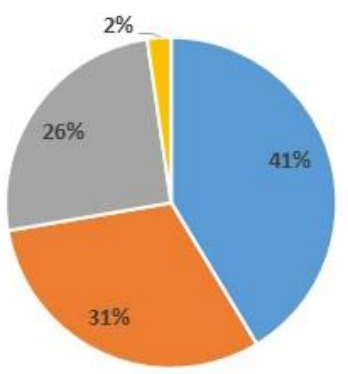

$$
\begin{aligned}
& \text { - Public relations professionals } \\
& \text { - Advertising and marketing professionals } \\
& \text { - Information and communications technology operations technicians } \\
& \text { " Advertising and public relations managers }
\end{aligned}
$$

Figure 3: Occupation Profiles of Vacancies in area ADMINISTRATION AND FINANCE
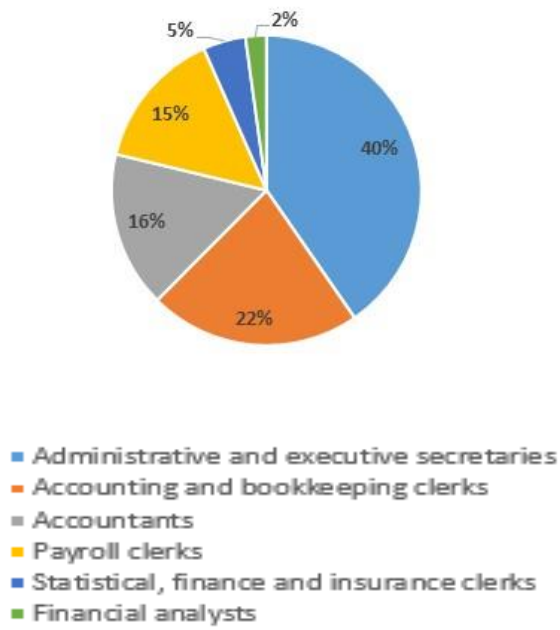

\section{Time Series ff Web Job Vacancies}

We collected more than 370,000 web job vacancies in the period between February 2013 and November 2016. Looking at the trend of the historical series, one can observe certain seasonal aspects within web labour market demand; this is the case with demand in August, when the number of web job vacancies is very low in comparison to July and September.

Overall the trend is positive; in the whole observed period (January 2016 to November 2016) one can note an increase in job vacancies of about $\mathbf{3 1 \%}$ in comparison to the same period of the previous year (or over 30,000 vacancies more). Focusing on each area, we can see the following.

- Sales Area. We collected more than 233,000 Web job vacancies in the period between February 2013 and November 2016. As one might easily observe, there 
was an increase of $\mathbf{3 2 \%}$ in demand for job vacancies for the period JanuaryNovember 2016 in comparison to the same interval of the previous year.

- Marketing and Communication. We collected more than 74,000 Web job vacancies in the period between February 2013 and November 2016. Here, there was an increase of $\mathbf{2 2 \%}$ in demand for job vacancies in the period JanuaryNovember 2016 in comparison to the same period of the previous year.

- Administration and Finance. There were more than 61,000 Web job vacancies in the period between February 2013 and November 2016. We can note an increase in job vacancies of about $\mathbf{3 8 \%}$ in comparison to the same period of the previous year.

Figure 4: Number of Vacancies by Month and by Area

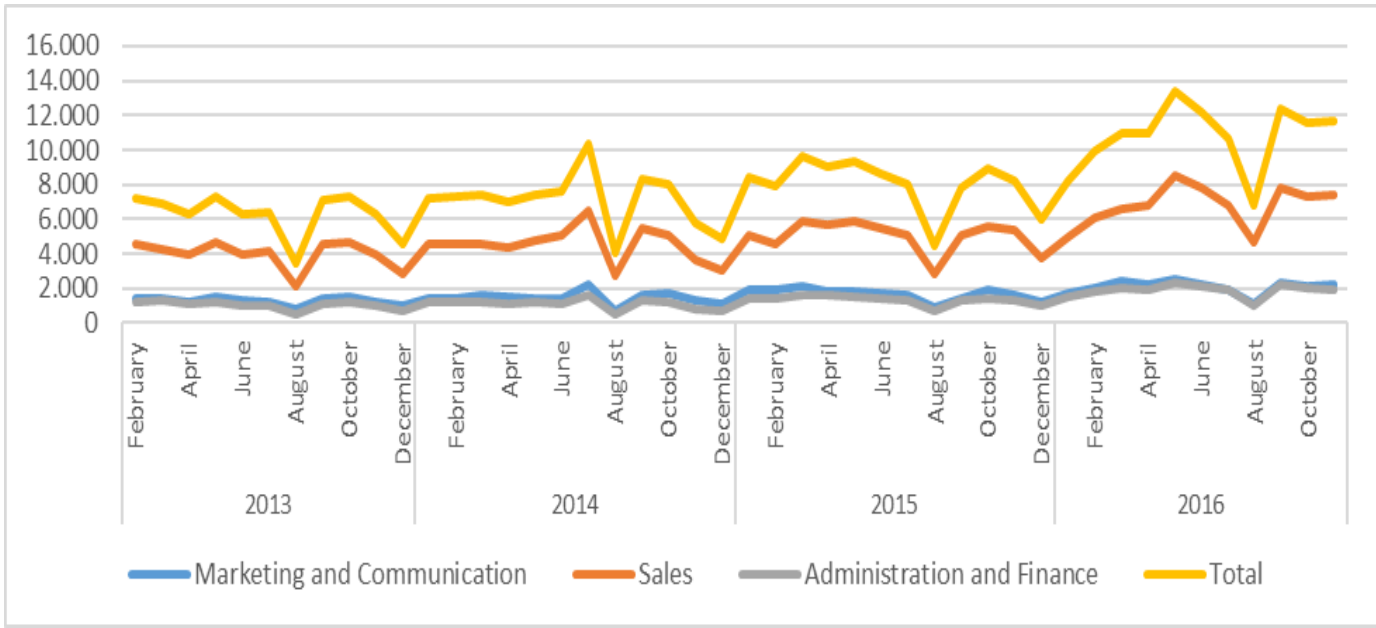

\section{Sector of Web Job Vacancies}

In this section we show the sectors specified within the vacancies over the three areas. Looking at Figure 2, we see that $40 \%$ of the vacancies are primarily in the "Wholesale/retail trade; motor repairs" sector. Then, $17 \%$ of the vacancies are related to the "Manufacturing" sector, whilst 12\% pertain to "Administrative and support service activities". All the remaining sectors account for less than $10 \%$.

However, each area has its own characteristics that diverge significantly from the others, namely:

- The "Wholesale/retail trade; motor repairs" sector dominates all the other sectors in the Sales area. Not surprisingly, this sector accounts for 55\%, while the "Manufacturing" sector only accounts for $16 \%$. Finally, the highest of all the other sectors represents at most $6 \%$.

- The "Professional, scientific and tech. activities" sector is the dominant one in the Marketing and Communication area with 23\%. Here, in contrast to the Sales area, the other sectors still have a significant proportion, as the "Wholesale/retail trade; motor repairs", the "Information and communication", and "Manufacturing" sectors account for 21\%, 19\% and 19\% respectively. Indeed, this area is more heterogeneous with respect to the Marketing and Communication area. Finally, in the Administration and Finance area the "Manufacturing" sector is predominant, though it only accounts for $19 \%$, 
followed by the "Professional, scientific and tech. activities" sector with $10 \%$ of share, while the "Financial and insurance activities" sector represents over $6 \%$ of the vacancies.

Figure 5: Sector of Vacancies by Area and Percentage

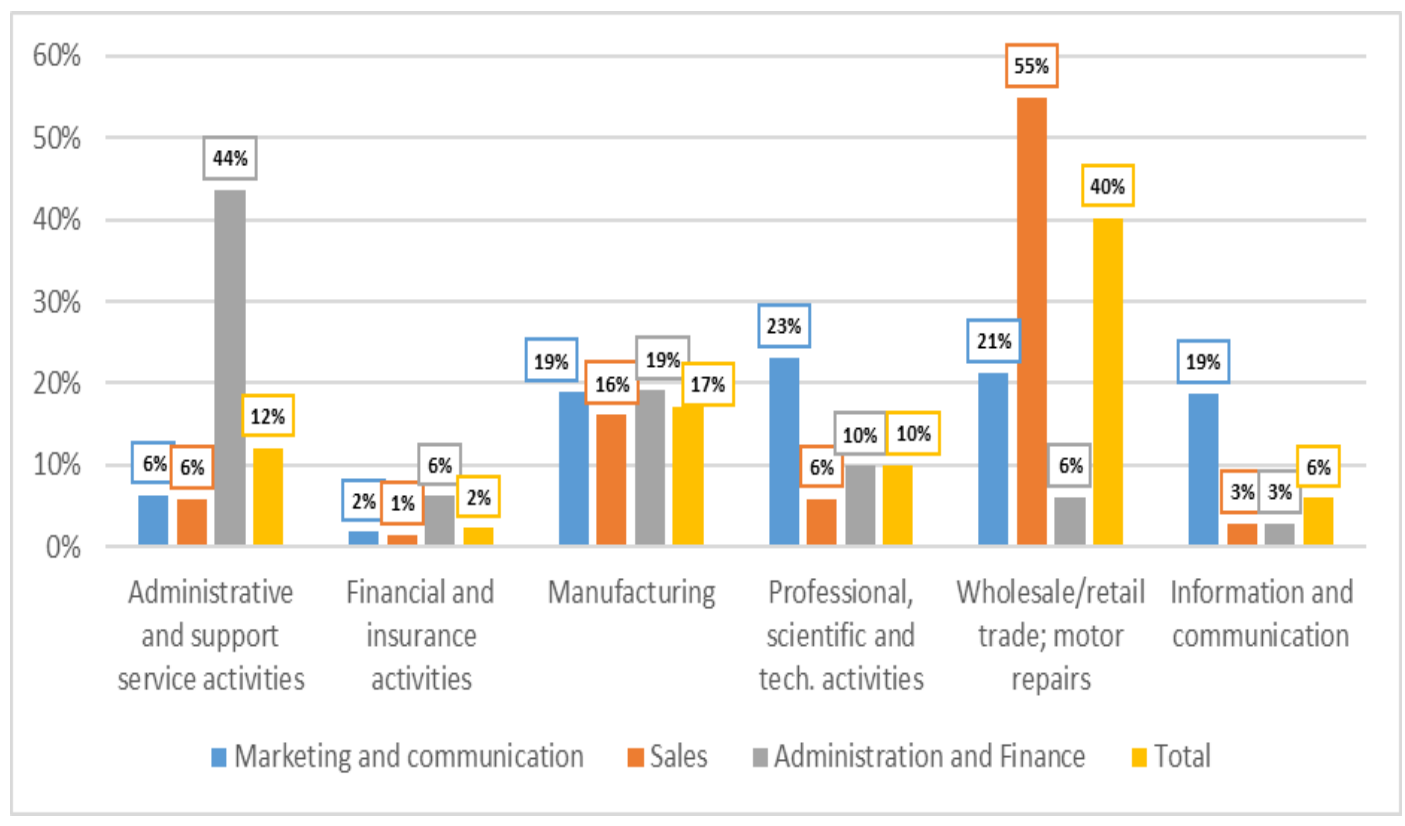

\section{Geographical Location}

The overall trend is of vacancies concentrated in the northern part of the country (approximately $74 \%$ of the vacancies). This is due to the population density of these areas and their favourable economic conditions, namely higher employment and lower unemployment.

The analysis by area confirms this tendency, as the great majority of vacancies are for jobs in Lombardy (e.g., 41\% of vacancies in the "Administration and Finance" area posted in Lombardy). The second region by number of vacancies is EmiliaRomagna accounting on average for about 13\%; it is followed by Veneto,where jobs in the Sales area are the predominant ones, and Piedmont with a share of $9 \%$. Finally, the Lazio region presents an average global share of $8 \%$ of the three areas as a whole, though the number of vacancies in Marketing and Communication (i.e., $10 \%$ ) it not negligible as it is comparable to the share of Piedmont, Veneto and Emilia-Romagna. 
Figure 6: Geographical Location of Vacancies by Area and Percentage

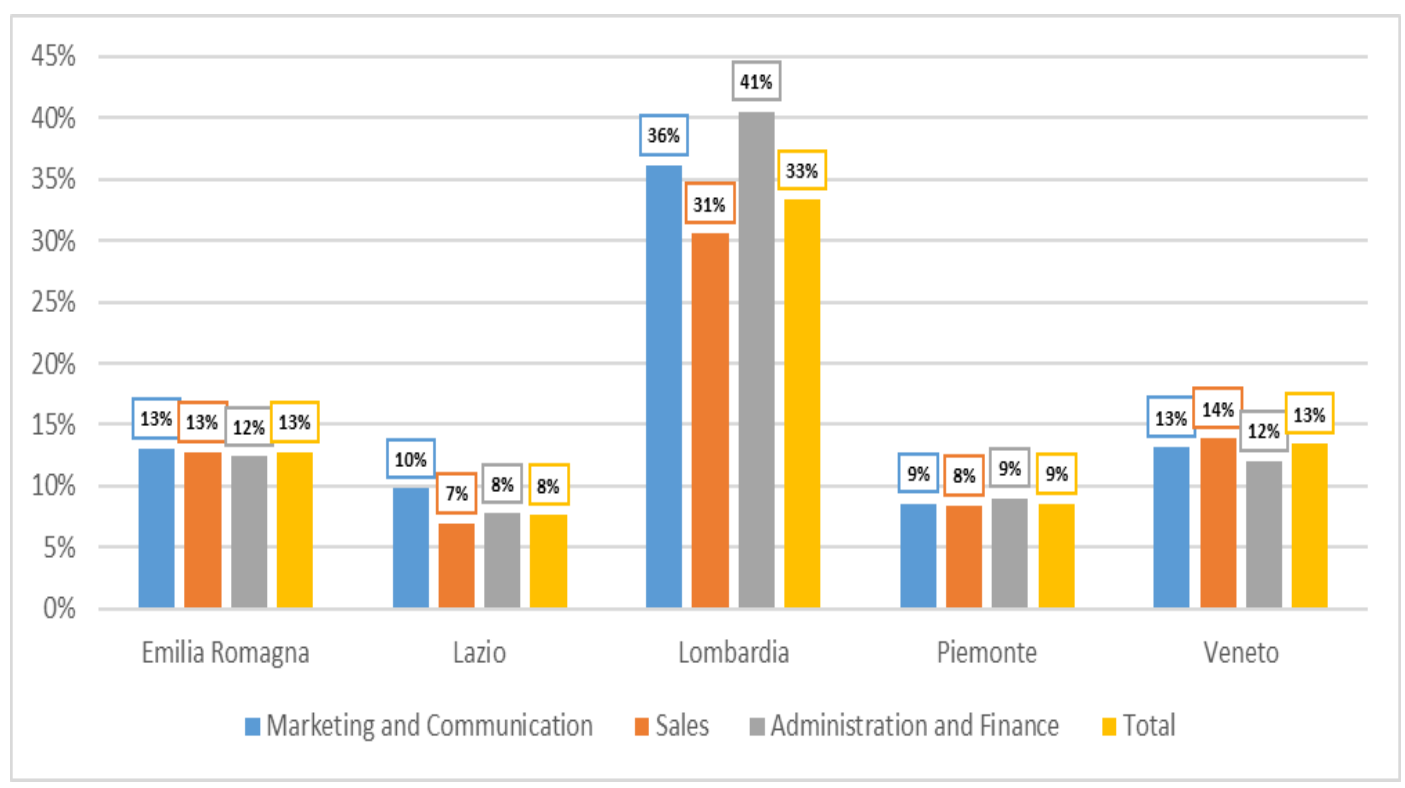

\section{Analyzing Hard and Soft Skills according to the Esco Taxonomy}

In this section we turn to some skills (both hard and soft) which we have extracted from job vacancies in each area. Table 2 shows the top 3 macro skills represented using the first level of the ESCO skills hierarchy. For each macro skill we also provide the frequency with which they appear in the vacancies. Similarly, for each macro skill we report on some skills recognized in the vacancies along with their frequency, using the fourth level of ESCO skills for their representation.

Not surprisingly, the relevance of computer science related skills surpasses the others for the Marketing and Communication area, though these are limited to the ability to use some basic information and communication tools. By contrast, skills related to the Business and Administration category are predominant in both Sales and Finance areas, mainly intended as ability in public relations, negotiations and management. Finally, a not negligible portion of skills in the area of Mechanical Engineering are requested for Sales and Marketing \& Communication areas (here intended as abilities in understanding technical schemas and the fundamentals of mechanics), whilst ability in performing data analysis is requested in the Finance Area, though to a lesser extent. Similarly, Table 3 show the soft ESCO skills. Here we can observe a quite similar distribution of the ESCO skills over the three areas. Indeed, language and communications competencies form most of the soft skill requirements, followed by the ability to work in a team. Finally, the ability to analyze problems also accounts for a not negligible part. It is worth remarking that these skills are extracted from Italian web job vacancies, and this explains the massive request for foreign languages, mainly referring to the knowledge of English, French, German, Spanish, or Chinese. 
Table 2: Top 3 Hard Skills identified within the Vacancies and expressed according to the ESCO taxonomy

\begin{tabular}{|c|c|c|c|}
\hline Area & Hard Skill & Hard Skill & Hard Skill \\
\hline Sales & $\begin{array}{c}\text { Business and } \\
\text { Administration }(59.67 \%) \\
\\
\text { Public relations }(43.11 \%) \\
\text { Management }(15.3 \%) \text { and } \\
\text { Administration of wages } \\
\text { (10.45\%) Selling } \\
\text { experience, Direct sales to } \\
\text { consumer (2.75\%) and } \\
\text { Experience in negotiations } \\
(2.74 \%)\end{array}$ & $\begin{array}{c}\text { MS Office suite (65.69\%) } \\
\text { SAP CRM (8.72) and } \\
\text { CAD/CASE tools (7.67\%) } \\
\text { Use of relational database } \\
(1.4 \%)\end{array}$ & $\begin{array}{l}\text { Mechanical Engineering } \\
\qquad(4.61 \%) \\
\text { Reading of technical } \\
\text { drawings (30.66\%) } \\
\text { Knowledge of mechanics } \\
\text { (30.24\%) } \\
\text { Machine tools, product } \\
\text { knowledge }(8.71 \%)\end{array}$ \\
\hline $\begin{array}{c}\text { Marketing \& } \\
\text { Communication }\end{array}$ & $\begin{array}{c}\text { MS Office Suite (23.84\%) } \\
\text { Use of relational database } \\
(30 \%) \\
\text { Use of graphics programs } \\
(5.1 \%)\end{array}$ & $\begin{array}{c}\text { Business and } \\
\text { Administration } \\
(29.94 \%) \\
\text { Public relations }(38.2 \%) \\
\text { Management and } \\
\text { organization }(22.91 \%) \text { and } \\
\text { Marketing }(6.04 \%) \\
\text { Customer relationship } \\
\text { management }(9.81 \%) \text { and } \\
\text { Sales management }(9.72 \%)\end{array}$ & $\begin{array}{c}\text { Mechanical Engineering } \\
\qquad(3.53 \%) \\
\\
\text { Reading of technical } \\
\text { drawings (33.12\%) } \\
\text { Knowledge of mechanics } \\
\text { (15.49\%) } \\
\text { Measuring technology } \\
(1.38 \%)\end{array}$ \\
\hline Finance & $\begin{array}{c}\text { Business and } \\
\text { Administration } \\
(49.52 \%) \\
\\
\text { Public relations }(23.4 \%) \\
\text { Management }(19.7 \%) \\
\text { Administration of wages } \\
(10.45 \%)\end{array}$ & $\begin{array}{c}\text { Informatics }(32.48 \%) \\
\\
\text { MS Office suite }(63.3 \%) \\
\text { SAP CRM }(17.3) \\
\text { Use of relational database } \\
\text { and business intelligence } \\
(3.4 \%)\end{array}$ & $\begin{array}{l}\text { Mathematics and Statistics } \\
\qquad(1.96 \%) \\
\text { Data analysis (100.0\%) }\end{array}$ \\
\hline
\end{tabular}

Table 3: Top 3 Soft Skills identified within the Vacancies and expressed according to the ESCO taxonomy

\begin{tabular}{|c|c|c|c|}
\hline Area & Soft Skill & Soft Skill & Soft Skill \\
\hline \multirow[t]{2}{*}{ Sales } & $\begin{array}{l}\text { Language and } \\
\text { Communication } \\
(57 \%)\end{array}$ & $\begin{array}{c}\text { Social Skills and } \\
\text { Competencies }(41.49 \%)\end{array}$ & $\begin{array}{c}\text { Thinking Skills and } \\
\text { Competencies }(1.51 \%)\end{array}$ \\
\hline & $\begin{array}{c}\text { Foreign language } e^{i i} \\
(97.56 \%) \\
\text { Mother tongue }(2.44 \%)\end{array}$ & $\begin{array}{c}\text { Working as part of a team } \\
(65.73 \%) \\
\text { Exercising responsibility } \\
(34.27 \%)\end{array}$ & $\begin{array}{l}\text { Analysing problems } \\
(100 \%)\end{array}$ \\
\hline \multirow[t]{2}{*}{$\begin{array}{c}\text { Marketing \& } \\
\text { Communication }\end{array}$} & $\begin{array}{l}\text { Language and } \\
\text { Communication } \\
(57.77 \%)\end{array}$ & $\begin{array}{c}\text { Social skills and } \\
\text { Competences }(40.79 \%)\end{array}$ & $\begin{array}{l}\text { Thinking skills and } \\
\text { competences }(1.51 \%)\end{array}$ \\
\hline & $\begin{array}{c}\text { Foreign language }{ }^{i i} \\
(98.38 \%) \\
\text { Mother tongue }(1.62 \%)\end{array}$ & $\begin{array}{c}\text { Working as part of a team } \\
(83.63 \%) \\
\text { Exercising responsibility } \\
(15.37 \%)\end{array}$ & $\begin{array}{c}\text { Analysing problems } \\
(100 \%)\end{array}$ \\
\hline Finance & $\begin{array}{c}\text { Language and } \\
\text { communication } \\
(57 \%) \\
\text { Foreign language } \\
(97.56 \%) \\
\text { Mother tongue }(2.44 \%)\end{array}$ & $\begin{array}{c}\text { Social Skills and } \\
\text { Competencies }(41.49 \%) \\
\text { Working as part of a team } \\
(65.73 \%) \\
\text { Exercising responsibility } \\
(34.27 \%)\end{array}$ & $\begin{array}{c}\text { Thinking Skills and } \\
\text { Competencies }(1.51 \%) \\
\text { Analysing problems } \\
(100 \%)\end{array}$ \\
\hline
\end{tabular}




\section{Identifying Potential New Occupations}

In this section we give an overview of the emerging potential new occupations in the areas identified. For the sake of clarity, we have to define the meaning of the term potential new occupation which, judging from our experience in the labour market field, is characterized by three representative elements which must occur together: first, the identified profession does not fit exactly into any of the designations from the ESCO taxonomy ${ }^{\text {iii; }}$; second, there must be already present a non-negative trend for such an occupation over the observed period; third, the potential new occupation cannot be expressed as the union of existing ones. This avoids the need to consider situations where a company is looking for a single employer to join together two distinct (and existing) profiles (e.g., analyst and software developer).

We used topic modeling algorithms to extract information about new emerging occupations from the web job vacancies. Documents composed of no more than 10 to 15 words were considered. The objective was to interpret the underlying themes within each document. Clearly, each document could include a mixture of themes (of different extents). LDA (Latent Dirichlet Allocation) (Blei, 2003) is a generative probabilistic model that considers each document as a mixture of latent topics, in which each topic is characterized by a probability distribution of the words that compose the topic itself. Thus, LDA allows clustering according to topics within each document on the basis of the frequency distribution that characterizes the document. As a result, each topic will contain the words that compose it, thus the higher the probability a word appears in the topic, the higher the relevance that the word has in its topic.

The idea here is to consider each job vacancy title as a document, as each job vacancy is potentially composed of a mixture of topics in terms of word distribution. Intuitively, new potential occupations will emerge from topics composed of words with (i) low probability distribution and (ii) classified over several ESCO codes, as they do not fit exactly in any ESCO job classification codes. Notice that focusing only on job titles (rather than on the full description) for identifying new potential occupations is significant, as we observed that employers often concentrate the most important part of the job vacancy content in a few words, and these frequently contain the job title offered.

Following the process described above, here we report an example of three potential new occupations, one for each area analyzed. Notice that here we report the job titles as they emerge from the vacancies along with a brief description we elaborated for summarizing the main duties.

Social Media Marketing. The job involves being in charge of communication activities through web/social campaigns. It also involves advertising products and services, analyzing users' feedback and disposition using sentiment analysis tools, and undertaking corresponding activities on the web to improve the corporate reputation.

Export Manager. This job involves the responsibility to empower the foreign market. Its main duty is to identify new countries for potential expansion and to elaborate effective strategies for strengthening the company's presence in the new countries identified.

Brand Manager. This job involves responsibility for the realization and implementation of marketing projects aimed at enhancing the reputation of a 
specific company's product. It also involves being in charge of the design, implementation and management of the production plan for a product line of a specific brand.

Focusing on the frequency of these three new potential occupations, we observed a massive request for Export Managers, as we found more than 2,800 vacancies posted in the period January 2013 - November 2016. More than 700 advertisements for Social Media Marketing were posted in the same period, while Brand Manager positions represented 500 vacancies. As we specified above, a non-negative trend is a necessary condition to mark an occupation as "potential new" occupation. This is the case of the three occupations we identified, as we observed a growing trend (see Figure 5). We compared the rates of growth for these occupations within the time frame of January-November 2016 with the same period of the previous year. This yielded the following results:

- Social Media Marketing, $+192.5 \%$

- Export Manager, $+56.4 \%$;

- Brand Manager, $+25.7 \%$

Figure 7: Number of Vacancies by Month and by New Potential Occupation

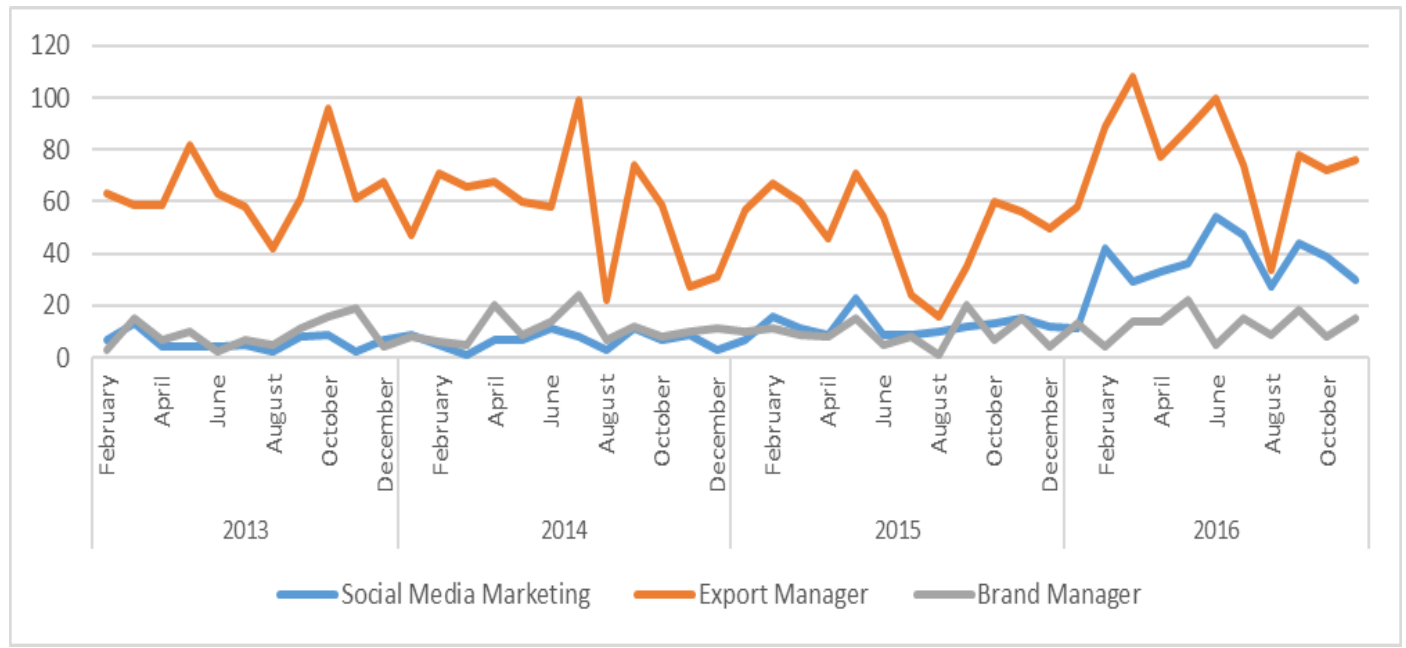

Concerning skills, we have to report a massive request for knowledge of the English language, as well as "professionalism", abilities in "public relations" and "working as part of a team". Conversely, the requests for hard skills slightly change for each occupation as follows.

Applicants for job vacancies for Social Media Marketing should possess abilities with Office suite and the PC as a baseline. More in depth, the analysis of the advertisements reveals demand for specific tools for the profession, such as Google Analytics, Google Adwords, Adobe Photoshop, HTML, WebEdit, CMS (Content Management Systems), just to cite a few. Finally, there is also a significant demand for abilities in analyzing data.

An Export Manager, however, should possess a broad knowledge of several foreign languages, such as French, German, Spanish, Chinese, and English as well. Then, he/she should know about "Management" especially in the sales area; he/she should have "Sales Experience", abilities in "Commercial development" and "Sales Management", along with a basic knowledge of the Office suite and experience in 
the sales. Similarly, a Brand Manager should possess a thorough understanding of the English language, abilities in "Public Relations", "Responsibility", and experience in the marketing field.

\section{Concluding Remarks}

For this paper we analyzed more than 1.9 million Italian web job vacancies from between 2013 and November 2016 using the WollyBI system. We focused on three distinct areas: (i) Marketing and Communication; (ii) Sales and (iii) Administration, Finance and Control. Each area was observed with regard to four aspects, namely trends, the sector specified in the vacancies, the job geographical distribution, and the skills requested (both hard and soft) for the vacancies.

Our results revealed a growing trend for all these areas. Specifically, the Sales area, which contains up to 233,000 vacancies, reported a significantly increased trend of $32 \%$ iv. The request for jobs in the Marketing area (more than 74,000 vacancies) reported a growth of $22 \%$ iv , while the Administration and Finance Area has grown by $38 \%$ iv . It is worth mentioning that this growing trend is also related to the increasing number of employers that have been using the web for advertising job positions.

Focusing on the sectors, we also observed a correspondence between each professional area and the sectors specified within the vacancy. Specifically, the vacancies for the "Sales" area present Wholesale/retail trade/motor repairs as the prevalent sector (55\%) while the sectors Professional, scientific and technical Activities and Wholesale/retail trade/motor repairs account for $23 \%$ and $21 \%$ respectively in the job vacancies. Finally, the predominant sector for Administration and Finance Area is Administrative and support service activities which accounts for $44 \%$ of the total.

Alongside this, the analysis at geographical level reveals that the region with the highest number of job vacancies in all the areas is Lombardy, having 41\%, 36\% and $31 \%$ of all the vacancies in the areas of Finance, Marketing and Communication, and Sales respectively.

We also used a topic modeling technique to identify new potential occupations as they emerge by analyzing the lexical matter used in the vacancies. We identified three distinct occupations with a growing trend in the most recent year, namely Social Media Marketing (+192\%), Export Manager (+56\%) and Brand Manager $(+25 \%)$. Finally, we extracted the main skills (both hard and soft) requested for these new potential occupations, shedding light on the relevance of the English language, abilities in using PC basics and Office, with a deeper knowledge of the web and graphic tools requested for Social Media Marketing.

In conclusion, we believe that analyzing the big data of the web labour market gives to analysts and labour market specialists the ability to observe how the labour market is evolving at a very fine-grained level, by extracting the most relevant skills as specified by employers. This, as a benefit, allows labour market specialists to observe at an early time labour market dynamics and trends, thereby assisting the "fact-based" decision making process.

The analysis of Web labour market data represents an opportunity to managers to monitor and catch timely the changes that are affecting the labour market in terms of both skills and occupations. This enables managers to promptly react to market 
changes, and to improve their own services and products according to the emerging needs of customers.

\section{Bibliography}

Amato, F., Boselli R., Cesarini M., Mercorio F., Mezzanzanica M., Moscato, V., Persia, F. \& Picariello, A. (2015). Challenge: Processing web texts for classifying job offers. IEEE International Conference on Semantic Computing. IEEE. 460-463.

Bimrose, J., \& Barnes, S.A. (2010). Labour market information (LMI), information communications and technologies (ICT) and information, advice and guidance (IAG). UK Commission for Employment and Skills (UKCES).

Blei, D.M., Andrew Y.N., \& Jordan, M.I. (2003). Latent dirichlet allocation. Journal of machine learning research, 993-1022.

Brondoni, S.M. (2015). Global Networks, Outside-In Capabilities and Smart Innovation, Symphonya. Emerging Issues in Management (symphonya.unimib.it), (1), 6 - 21.

http://dx.doi.org/10.4468/2015.1.02brondoni

Brondoni S.M. (2011). Global Networks, Knowledge Management and World Cities, Symphonya. Emerging Issues in Management (symphonya.unimib.it), (1), 7-18.

http://dx.doi.org/10.4468/2011.1.02brondoni

Dusi, S., Fontana M., Mercorio F., \& Mezzanzanica M. (2016). Analysing the Relevance of ICT Skills on occupations in Web Job Vacancies. In Digital $(R)$ Evolution and Its Effects on Labour: Opportunities and Challenges for Regional and Local Labour Market Monitoring, 31-44. Rainer Hampp Verlag.

Elias, P., \& Purcell, K. (2004). SOC (HE): A classification of occupations for studying the graduate labour market. Institute for Employment Research, University of Warwick, Coventry, UK.

Eurostat (2016). Labour force survey. Available at http://ec.europa.eu/eurostat/web/microdata/european-union-labour-force-survey.

Fayyad, U., Piatetsky-Shapiro, G., \& Smyth, P. (1996). The KDD process for extracting useful knowledge from volumes of data. Communications of the ACM, 39(11), 27-34.

Lee, I. (2011). Modeling the benefit of e-recruiting process integration. Decision Support Systems (Elsevier), 51(11), 230-239.

Sebastiani, F. (2002). Machine learning in automated text categorization. ACM computing surveys . ACM Computing Surveys (ACM), 1-47.

The European Commission. (2010). An agenda for new skills and jobs: A european contribution towards full employment (com(2010) 682, 23.11.2010). Available at: http://goo.gl/lkqt7o.

The European Commission. (2008). New skills for new jobs (com(2008) 868, 16.12.2008). Available at http://goo.gl/xdwpz9 .

\footnotetext{
Notes

${ }^{\mathrm{i}}$ https://ec.europa.eu/esco/portal/browse

ii Notice: it includes English, French, German, Spanish, Chinese

iii The classification of web job vacancies is performed by automatic machine learning algorithms that estimates the accuracy of the prediction through which one can obtain useful insights about the effectiveness of the classification.

iv Growing tendency computed by comparing the 2016, January-November period against the same period of the previous year.
} 